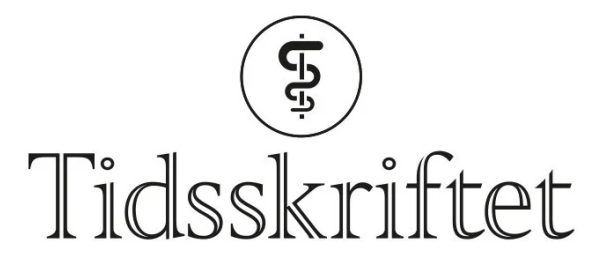

DEN NORSKE LEGEFORENING

\title{
Riktig behandling for stramt tungebånd hos spedbarn
}

DEBATT

\section{SOLVEIG THORP HOLMSEN}

solveig.holmsen@diakonsyk.no

Solveig Thorp Holmsen er master of public health, lege i spesialisering i samfunnsmedisin, lege og medisinsk rådgiver ved Nasjonal kompetansetjeneste for amming og overlege ved Oslo skadelegevakt, Oslo universitetssykehus. Hun er ph.d.-stipendiat ved Universitetet i Oslo, der hun forsker på stramt tungebånd hos spedbarn.

Forfatteren har fylt ut ICMJE-skjemaet og oppgir følgende interessekonflikter: Hun har deltatt i arbeidsgruppen som har utarbeidet Veileder for diagnostikk og behandling av stramt tungebånd hos spedbarn.

\section{ANN-MAGRIT LONA}

Ann-Magrit Lona er helsesykepleier med videreutdanning i ammeveiledning, sertifisert International Board Certified Lactation Consultant (IBCLC) og prosjektleder i AmmE-læring, et nett kurs i ammeveiledning for helsepersonell.

Forfatteren har fylt ut ICMJE-skjemaet og oppgir følgende interessekonflikter: Hun har deltatt i arbeidsgruppen som har utarbeidet Veileder for diagnostikk og behandling av stramt tungebånd hos spedbarn.

\section{RØNNAUG SOLBERG}

Rønnaug Solberg er ph.d., spesialist i barnesykdommer, neonatolog, overlege ved Sykehuset i Vestfold og forsker ved Pediatrisk forskningsinstitutt, Oslo universitetssykehus.

Forfatteren har fylt ut ICMJE-skjemaet og oppgir følgende interessekonflikter: Hun har vært leder for arbeidsgruppen som har utarbeidet Veileder for diagnostikk og behandling av stramt tungebånd hos spedbarn.

\section{Stramt tungebånd hos spedbarn kan gi ammevansker. En ny kunnskapsbasert veileder for helsepersonell vil gjøre det lettere å få hjelp.}

Helsepersonell i Norge har lenge etterspurt en faglig veileder om stramt tungebånd hos spedbarn. Dersom stramt tungebånd gir ammeproblemer, tilbys først ammeveiledning. Dersom dette ikke fører frem, kan man vurdere å klippe tungebåndet. Kunnskapsgrunnlaget for denne hovedanbefalingen er tilstrekkelig og i tråd med UpToDate og andre internasjonale retningslinjer. 
Stramt tungebånd hos spedbarn kan gi ammevansker. Hos noen kan det føre til manglende vektoppgang hos barnet og smertefull amming for mor (1). I Norsk barnelegeforenings pediatriveileder inngår en kortfattet prosedyre for diagnostikk og behandling av stramt tungebånd hos nyfødte (므). En nasjonal tverrfaglig arbeidsgruppe har nå utarbeidet en mer detaljert veileder for helsepersonell (3).

\section{Kunnskapsbasert hjelp til amming}

Nesten alle mødre i Norge begynner å amme, men allerede ved fire måneders alder får bare $39 \%$ av spedbarna kun morsmelk (4). Mødre rapporterer om ammeproblemer som årsak til at de ikke fullammer eller til at de må avslutte amming før de ønsker (4). Stramt tungebånd er én av mange årsaker til ammevansker.

Ammeproblemene kan påvirke barnets vekst og trivsel og morens fysiske og psykiske helse. Å gjøre det mulig for mødre å amme i tråd med helsemyndighetens anbefalinger bidrar til bedre helse for barn og mor (5). Det er derfor av stor betydning at helsepersonell kan gi kvalifisert ammeveiledning og utrede årsaker til ammevansker, deriblant diagnostisere og behandle stramt tungebånd. Formålet med den nye veilederen er å bidra til kunnskapsbasert diagnostikk og behandling av symptomgivende stramt tungebånd.

\section{Forekomst og behandling}

Tungebåndet ligger i midtlinjen mellom undersiden av tungen og munngulvet og består av bindevevsfascie og slimhinne (므). Stramt tungebånd er en medfødt misdannelse som ifølge en Cochrane-oversikt forekommer hos omtrent 4-11 \% av nyfødte (7.). Litteraturen angir at ammeproblemer kan oppstå hos 25-60 \% av spedbarn med stramt tungebånd (1). I 2019 fikk $2,8 \%$ av spedbarn født i Norge diagnosen, og 2,2 \% ble behandlet med klipping av tungebåndet (므). Økt kunnskap og oppmerksomhet om tilstanden kan være en årsak til at rapportert forekomst i Norge har økt de senere årene. Behandling av 2,2 \% av nyfødte kan være indisert ut fra forekomst og hvor mange spedbarn som har symptomgivende stramt tungebånd.

\section{Ammevansker}

Ultralydundersøkelser viser at tungen i en normalsituasjon har en svært aktiv rolle i overføringen av melk fra bryst til barn, der tungen via peristaltiske bevegelser presser brystvevet opp mot ganen og bidrar til at det dannes vakuum (9.). Vakuum og tungens bevegelser er hovedmekanismen for overføring av melk.

\section{«Dersom stramt tungebånd gir ammeproblemer, tilbys først ammeveiledning»}

Hvis stramt tungebånd reduserer tungens bevegelighet og funksjon, kan det føre til problemer med suging og svelging. Barnet får dårlig dietak og mindre brystvev i munnen, noe som kan resultere i såre brystknopper og dårlig tømming av brystet. Dette er kjente risikofaktorer for utvikling av mastitt. Behov for hyppig amming og at hvert måltid tar lang tid, er vanlig ved symptomgivende stramt tungebånd hos spedbarn. Graden av symptomer varierer fordi hvert mor-barn-par er ulike, med forskjellig anatomi og fysiologi. For noen mødre blir problemene så store at de må avslutte ammingen før de egentlig ønsker $(\underline{10}, \underline{11})$.

\section{Første tiltak: ammeveiledning}


Flere av symptomene på stramt tungebånd er uspesifikke, og diagnosen og behandlingen er omdiskutert $(\underline{8}, \underline{12})$. Kvalifisert ammeveiledning er viktig, slik at mer vanlige årsaker til ammeproblemer håndteres først. Hvis ammeveiledning ikke bedrer situasjonen, må spedbarn med stramt tungebånd og redusert tungefunksjon undersøkes og behandles av helsepersonell med kunnskap om problemstillingen (13).

Symptomgivende stramt tungebånd kan behandles med en enkel prosedyre, der tungebåndet klippes. Det er liten risiko for komplikasjoner når prosedyren utføres av kvalifisert helsepersonell (13). Grad av smerte ved prosedyren er vurdert å være lav (14,15). I veilederen inngår anbefalinger om forebygging og behandling av smerte (3).

\section{Tilstrekkelig evidens}

Spedbarn skal kun behandles for stramt tungebånd når indikasjon foreligger (13). Det mangler effektstudier av høy kvalitet (7.). I kliniske oppslagsverk som UpToDate (13) og den samlede forskningen fra små randomiserte studier, oppfølgingsstudier samt kasuistikker finner man imidlertid at klipping av tungebånd etter riktig indikasjon er assosiert med bedret amming $(7, \underline{13}, \underline{16})$. Dette er også behandleres og pasienters (mødres) erfaring, noe det skal tas hensyn til ved utarbeiding av veiledninger for kunnskapsbasert praksis.

\section{«Klipping av tungebånd etter riktig indikasjon er assosiert med bedret amming»}

Som ved all annen medisinsk behandling av spedbarn er det foreldrenes samtykke som gjelder. Vår erfaring er at mødre ofte har strevd lenge med ammingen, med risiko for tidlig ammeslutt, før de henvises. De kan ha vært behandlet for sårinfeksjon, hatt flere mastitter og barnet har ikke hatt vektøkning som forventet. Dette er kompliserte problemstillinger som ikke går over av seg selv. Oppfølging med ammeveiledning bør tilbys uansett om tungebåndet klippes eller behandles konservativt, med mål om å få til velfungerende amming for mødre som ønsker det.

Veileder for diagnostikk og behandling av stramt tungebånd hos spedbarn er utarbeidet av en landsdekkende arbeidsgruppe, bestående av nyfødtmedisinere, pediatere, øre-nese-halsleger, tannlege, logoped, jordmødre, helsesykepleiere, allmennleger og samfunnsmedisinere samt brukerrepresentanter etter initiativ fra Nasjonal kompetansetjeneste for amming (NKA). Veilederen kan leses og lastes ned fra kompetansetjenestens nettside (3).

\section{LITTERATUR}

1. Segal LM, Stephenson R, Dawes M et al. Prevalence, diagnosis, and treatment of ankyloglossia: methodologic review. Can Fam Physician 2007; 53: 1027-33. [PubMed]

2. Vatne AHS, Tjora T, Størdal K et al. Pediatriveiledere: Stramt tungebånd hos nyfødte. Norsk barnelegeforening. https://www.helsebiblioteket.no/pediatriveiledere? menuitemkeylev1 $=11574 \& k e y=262401$ Lest 23.8.2021.

3. Oslo universitetssykehus. Nasjonal kompetansetjeneste for amming. Veileder for diagnostikk og behandling av stramt tungebånd hos spedbarn. https://oslo-universitetssykehus.no/fag-ogforskning/nasjonale-og-regionale-tjenester/nasjonal-kompetansetjeneste-for-amming-nka/fagstoffom-amming-og-morsmelk/kliniske-problemstillinger\#veileder-for-diagnostisering-og-behandlingav-stramt-tungeband-hos-spedbarn Lest 23.8.2021.

4. Myhre JB, Andersen LF, Kristiansen AL. Spedkost 3. Landsomfattende undersøkelse av kostholdet blant spedbarn i Norge, 6 måneder. Oslo: Folkehelseinstituttet, 2020. https://www.fhi.no/globalassets/dokumenterfiler/rapporter/2020/kostholdsundersokelser/spedkost3---barn-6-mnd-alder.pdf Lest 23.8.2021. 
5. Victora CG, Bahl R, Barros AJD et al. Breastfeeding in the 21st century: epidemiology, mechanisms, and lifelong effect. Lancet 2016; 387: 475-90. [PubMed][CrossRef]

6. Mills N, Pransky SM, Geddes DT et al. What is a tongue tie? Defining the anatomy of the in-situ lingual frenulum. Clin Anat 2019;32: 749-61. [PubMed][CrossRef]

7. O'Shea JE, Foster JP, O'Donnell CP et al. Frenotomy for tongue-tie in newborn infants. Cochrane Database Syst Rev 2017; 3: CDo11065. [PubMed]

8. Haug AC, Markestad T, Tjora E et al. Stramt tungebånd hos nyfødte. Tidsskr Nor Legeforen 2021; 141. doi:10.4045/tidsskr.21.0515. [CrossRef]

9. Elad D, Kozlovsky P, Blum O et al. Biomechanics of milk extraction during breast-feeding. Proc Natl Acad Sci U S A 2014; 111: 5230-5. [PubMed][CrossRef]

10. Ricke LA, Baker NJ, Madlon-Kay DJ et al. Newborn tongue-tie: prevalence and effect on breastfeeding. J Am Board Fam Pract 2005; 18:1-7. [PubMed][CrossRef]

11. Hogan M, Westcott C, Griffiths M. Randomized, controlled trial of division of tongue-tie in infants with feeding problems. J Paediatr Child Health 2005; 41: 246-50. [PubMed][CrossRef]

12. Obladen M. Much ado about nothing: two millenia of controversy on tongue-tie. Neonatology 2010; 97: 83-9. [PubMed][CrossRef]

13. Isaacson GC, Armsby C. Ankyloglossia (tongue-tie) in infants and children: UpToDate. https://www.uptodate.com/contents/ankyloglossia-tongue-tie-in-infants-and-children? source=history_widget Lest 23.8.2021.

14. Tongue-tie NHS. https://www.nhs.uk/conditions/tongue-tie/ Lest 19.8.2021.

15. Mayo Clinic. Tongue-tie (ankyloglossia). https://www.mayoclinic.org/diseases-conditions/tonguetie/diagnosis-treatment/drc-20378456 Lest 19.8.2021.

16. Francis DO, Krishnaswami S, McPheeters M. Treatment of ankyloglossia and breastfeeding outcomes: a systematic review. Pediatrics 2015; 135: e1458-66. [PubMed][CrossRef]

Publisert: 26. august 2021. Tidsskr Nor Legeforen. DOI: 10.4045/tidsskr.21.0520

Mottatt 29.6.2021, første revisjon innsendt 20.8.2021, godkjent 23.8.2021.

(C) Tidsskrift for Den norske legeforening 2023. Lastet ned fra tidsskriftet.no 26. april 2023. 